\title{
Medical response to the Great East Japan Earthquake in Ishinomaki City
}

\author{
Tadashi Ishii*
}

Problem: The Ishinomaki Red Cross Hospital is the only designated disaster hospital in the Ishinomaki Medical Zone, Japan that was undamaged from the Great East Japan Earthquake in March 2011. The tsunami completely destroyed a large part of the Ishinomaki Medical Zone.

Context: The Ishinomaki Red Cross Hospital was designed with the capability to respond to disasters. An instruction manual for responding to disasters had been developed and was exercised through drills.

Action: In accordance with the manual, the hospital disaster task force was established. The Ishinomaki Zone Joint Relief Team coordinated medical support from organizations such as physicians associations, dental associations, self-defence forces medical teams, pharmacists associations, the Japanese Red Cross and relief teams from hospitals all over the country. In three days, the joint relief team directly visited all emergency shelters to make an initial assessment and to collect information about the number and state of health of evacuees, provision of food and drinking water and the availability of electricity, water and sewerage.

Outcome: Initial assessment revealed that 35 emergency shelters lacked a sufficient food supply and that 100 shelters had unsanitary conditions. The joint relief team provided the Miyagi Prefecture government and the Ishinomaki municipal government with information about emergency shelters that did not have sufficient food supply. As of 30 September, the activities of the joint relief team were completed, and there was no outbreak of communicable diseases in the Ishinomaki Medical Zone. A total of 328 shelters with 46480 evacuees were managed by the Ishinomaki Zone Joint Relief Team.

Discussion: Advanced preparation to quickly establish an initial response system, expertise, and decision-making ability and the ability to get things done are required for disaster response management.

\section{PROBLEM}

Located in Ishinomaki City in Miyagi Prefecture, the Ishinomaki Red Cross Hospital is the only designated disaster hospital in the Ishinomaki Medical Zone consisting of Ishinomaki City, Onagawa-cho and Higashimatsushima City. In addition to emergency rescue, which is the basic mission of the Japanese Red Cross Society, the organization had been given the role of accepting and transporting the sick and injured in the disaster area. The applicable population is 220 000. The headquarters for Japan's Earthquake Research Promotion announced on 12 January 2010 (published only on their website) that there was a $99 \%$ probability of an earthquake occurring offshore from Miyagi Prefecture within the next 30 years. ${ }^{1}$ The Great East Japan Earthquake struck on Friday, 11 March 2011 at 14:46.

\section{CONTEXT}

In May 2006, because the building of the Ishinomaki Red Cross Hospital was aging, the hospital was moved from the Minato Ward on the coast further inland where the risk of tsunami damage would be minimal. At that time, measures were devised to better prepare the facilities for disasters, including earthquakes. The new hospital was provided with a seismically isolated structure and equipped with a ground heliport in case the elevator ceased to function and prevented access to the heliport on top of the building. The entrance was widened to accommodate a potentially large number of disaster victims, and oxygen outlets were provided at four locations along one wall for patients in need of oxygen.

At the end of 2007, the hospital disaster manual was revised to provide more specific information such as

*Ishinomaki Zone Joint Relief Team Supervisor, Miyagi Prefecture Disaster Medical Coordinator, Ishinomaki Red Cross Hospital (e-mail: t-ishi23@green.ocn.ne.jp) Submitted: 8 October 2011; Published: 23 December 2011

doi: 10.5365/wpsar.year.2011.2.4.005 
the name of the person in charge of each department. Based on the new manual, a tabletop exercise for dealing with a major disaster was conducted in January 2008, and an actual drill was conducted in July of that year. In June 2010, Miyagi Prefecture and Ishinomaki Red Cross Hospital jointly conducted a helicopter training exercise to test the response to a hypothetical disaster in Miyagi Prefecture. The exercise consisted of receiving and transporting simulated patients during a major disaster.

In January 2010, a network council of those in charge of disaster medical care in the Ishinomaki area was established. The council was formed to coordinate the efforts of pertinent institutions such as the fire, public health and police departments, self-defence forces, medical associations and nearby hospitals.

In September 2010, the hospital concluded an agreement of support with the telecommunications company NTT DoCoMo Shop Ishinomaki; Sekisui House, Ltd., a construction company; and the Shisuikai (a community of restaurants and drinking establishments in the city of Ishinomaki). According to the agreement, NTT DoCoMo Shop Ishinomaki would provide telecommunications equipment such as satellitebased mobile telephones, Sekisui House would provide tents, and the Shisuikai would prepare meals in the hospital.

\section{ACTION}

\section{Initial hospital response according to the manual}

The hospital switched to its own backup power generation several seconds after electrical power was interrupted immediately following the earthquake. In accordance with the hospital manual, a hospital disaster task force was immediately established, and a Level 3 emergency was declared. Level 3 is an in-house stipulation, whereby, if a large number of disaster victims are expected, all normal work at the hospital is cancelled and replaced by response to disaster victims. The conditions in the hospital related to the disaster and vital infrastructures were checked in accordance with the manual. Hearing that a tsunami had surged through the streets of Ishinomaki City; that there were thousands of fatalities; and that the city, including the municipal government buildings, was submerged, the operating premise was that the initial reaction function of the Ishinomaki municipal government would be limited.

\section{Establishment of the Ishinomaki Zone Joint Relief Team and coordination of medical support}

On 12 March, relief teams from outside the stricken area gathered at the hospital (13 Japanese Red Cross teams and four Disaster Medical Assistance Teams [DMATs]) (Figure 1). Because comprehensive disaster information was not initially available, the relief teams were sporadically sent to nearby emergency shelters or isolated areas by request of the self-defence forces and the fire brigade. On 13 March, Ogatsu, the southern portion of Higashimatsushima City and the south beach of Ishinomaki City were completely destroyed, as were Kitakami-cho and Oshika on 15 March. In order to efficiently and effectively utilize medical resources with a limited number of relief teams, on 18 March, it was decided to coordinate various pertinent institutions such as the Miyagi Prefecture government; the Ishinomaki municipal government; the Higashimatsushima municipal government; the Onagawa-cho government; the local medical association; the local dental association; the local pharmacists association; the Tohoku University Hospital; and Northeast, North and Central selfdefence forces. The Ishinomaki Zone Joint Relief Team was established on 20 March. The joint relief team was organized so that all teams could work together in a coordinated effort. Teams included physicians associations, dental associations, self-defence forces, medical teams and pharmacists associations. Japanese Red Cross relief teams and relief teams from hospitals all over the country, primarily public hospitals such as prefectural hospitals via the Miyagi Prefecture government, also participated, The joint relief team decided the daily course of action and plotted the long-term course for future strategy by consulting with 22 experts from across Japan with a wealth of experience in disaster medical care and with knowledge of organization management.

\section{Assessment and support of emergency shelters}

On 16 March, the water receded from the areas surrounding the government offices, making access possible, and a list of emergency shelters was received from the municipal government. 


\section{Figure 1. Relief teams dispatched in Ishinomaki in the first week of the response following the Great East Japan} Earthquake

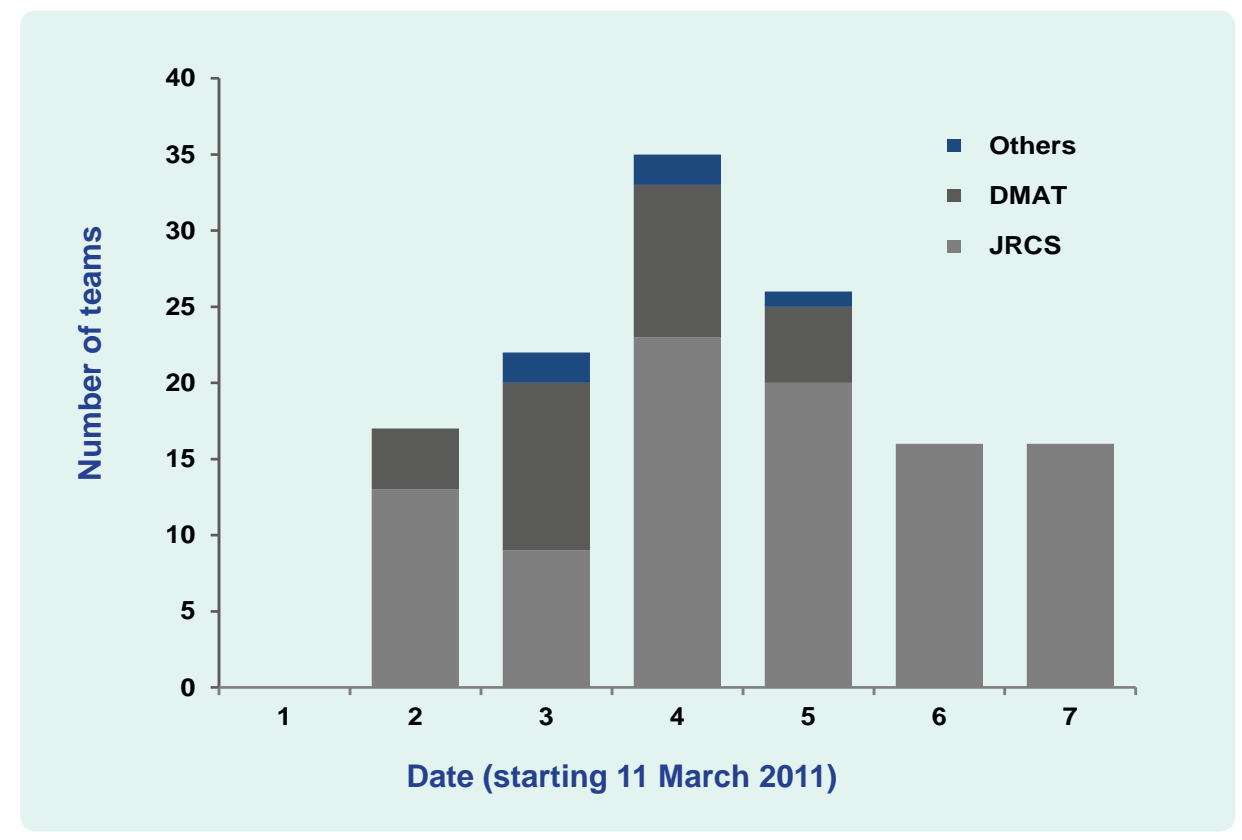

DMAT - Disaster Medical Assistant Team; JRCS - Japanese Red Cross Society

There were about 300 emergency shelters in Ishinomaki City, Higashimatsushima City and Onagawa-cho. The list gave the name of the shelter and the number of evacuees but did not provide details about the conditions at the shelters. Because DMATs' activities were limited to 48 hours, they withdrew on 16 March, leaving only 16 Japanese Red Cross relief teams on hand on 17 March (3 more teams than on 12 March) (Figure 1). In order to get the most out of such limited medical resources, the relief teams split up and directly visited all emergency shelters to make initial assessments. After receiving the assessments, the Ishinomaki Zone Joint Relief Team task force determined the course of action for each relief team.

In addition to the number and state of health of evacuees (fever, cough, diarrhoea, vomiting, influenza, respiratory problems, etc.), the initial assessment contained information concerning provision of food and drinking water, availability of electricity and water/ sewerage, access to means of keeping warm such as blankets and heaters and sanitation of toilet facilities. The relief teams collected this information from the emergency shelters each day, thus enabling the proper measures to be taken in coordination with local governments to the maximum degree possible. The assessment forms were designed to evaluate the 300 different shelters in order to better aggregate their information. The shelters were graded using a four-tier coding system (excellent, good, bad, very bad). The grading was carried out by each relief team. It was necessary to collect information as quickly as possible, so the criteria for neutral and negative ratings were omitted from the manual to save time, leaving the subjective judgment to those in the field.

\section{OUTCOMES}

\section{Initial hospital response according to the manual}

All patients and employees in the hospital were unharmed. Physical damage to the hospital was minimal; with the exception of the gas supply, everything had escaped damage including testing equipment. There was a three-day supply of water including general service water. There was also a three-day supply of food for patients.

The triage area was set up as stipulated by the manual at 15:43, roughly an hour after the earthquake struck. Sekisui House came to the hospital immediately and set up tents in front of the entrance. Immediately following the earthquake, NTT DoCoMo Shop Ishinomaki provided ten mobile telephones with 
priority connections and two satellite-based mobile telephones (one of which was provided prior to the disaster). Conventional mobile telephones, land lines, e-mail and Internet service became unavailable approximately two hours following the disaster. Until NTT DoCoMo Shop Ishinomaki set up a base station nearby on 17 March, the only telecommunications available were satellite-based mobile telephone and emergency wireless telecommunications.

The Ishinomaki Red Cross Hospital treated 3938 patients within the first seven days after the disaster. Forty-eight hours after the disaster, the hospital treated 115 patients, $26.1 \%$ of whom suffered from hypothermia, which was the most common ailment.

\section{Establishment of the Ishinomaki Zone Joint Relief Team and coordination of medical support}

Revisions to mobilization criteria for the Japanese Red Cross relief teams in 2009 gave the directors of hospitals affiliated with relief teams the authority to send teams to the stricken area, enabling local Japanese Red Cross relief teams to go into action quickly. Japanese Red Cross and non-affiliated relief teams from all over the country that had gathered in the Ishinomaki area were registered for participation in the joint relief team beginning 20 March. The number of teams increased by as many as 59 teams on a single day on 26 March (100 physicians). It was truly an "all Japan" team. By 30 September, some 3633 relief teams participated in the joint relief team; the Japanese Red Cross relief team consisted of 1078 teams, and the remaining two-thirds were other than Japanese Red Cross.

Each relief team was active an average of four to five days. With this many relief teams, several teams were always coming and going. The cities of Ishinomaki, Higashimatsushima and Onagawa-cho were divided into 14 areas based on the distribution of emergency shelters. Relief teams were allocated to each area as needed; one of the teams was designated as the managing team to decide the next day's activities in the area, thus providing the teams with autonomy of activities. A "line" was established whereby multiple teams were coordinated at the site into team 1 , team 2, team 3 and so forth in order to have participating relief teams continuously performing activities. One line operated as one team, not simultaneously as individual teams. The line teams were given instructions and then deployed to affected areas by a co-ordinating headquarters which was set up at the Ishinomaki Red Cross Hospital on 28 March. Elsewhere, general meetings were held each day by the task force to determine the needs of each area, get opinions, coordinate activities and decide the overall course of activities. In addition to daily assessment data and meetings, reports on each area were heard, emergency medical needs were assessed and the number of lines required for each area was revised each day. Medical needs for emergency shelters gradually decreased as infrastructure such as water and sewerage was restored and privatepractice physicians began working again. The activities of the joint relief team were completed by the end of September 2011.

A total of 328 shelters with 46480 evacuees were managed by the Ishinomaki Zone Joint Relief Team, and 53696 people were seen at evacuation centres during the relief teams' visits until activities ended.

The fire department dispatched resident liaisons to emergency centres and heliports to take charge of ambulances and helicopter control. The police department provided public security information. The Ishinomaki municipal government sent representatives to the relief team meetings to work with them. The self-defence forces took the lead in patrolling areas that were dangerous to access and provided helicopters to cover isolated islands. Some 2334 pharmacists from the Miyagi Prefecture Pharmacists Association provided assistance. The emergency department of the hospital accepted patients from emergency shelters and first aid stations without restriction and required no letter of referral.

\section{Assessment and support of emergency shelters}

Initial assessments started on 17 March and were completed in three days. During this time, there were 93 emergency transports from emergency shelters (overall total of 313) in Ishinomaki City, Higashimatsushima City and Onagawa-cho, which accounted for $29.7 \%$ of the total number of transports. Assessments of emergency shelters were subsequently updated each time the rounds were made, and the data were recorded and kept in chronological order to get a good understanding of the variation in the number of 


\section{Figure 2. Wrap-type toilet used in evacuation centres}

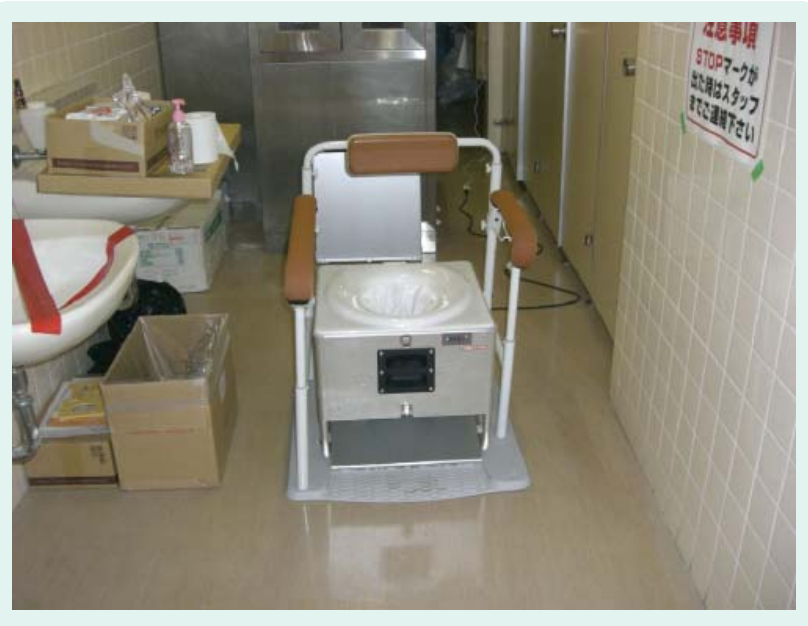

patients with symptoms and various tendencies. Initial assessments revealed that 35 emergency shelters lacked a sufficient food supply and that 100 shelters were contaminated by sludge and dust and had unsanitary conditions such as toilets that could not flush because of damage to the water and sewerage systems.

The Miyagi Prefecture government and the Ishinomaki municipal government was provided with information about insufficient food supplies in emergency shelters, and the Miyagi Prefecture government addressed the problem.

The joint relief task force enlisted the cooperation of contractors to provide 90 wrap-type portable toilets that were stored in Higashimatsushima City and distributed to emergency shelters in the Ishinomaki area that needed them. These toilets, primarily for the elderly who have a hard time getting about, can be set indoors. The western style, wrap-type toilets (waste is solidified by chemicals for sanitary disposal) put minimal stress on the knees (Figure 2).

Two contamination-control certified nurses at the hospital visited each emergency shelter where conditions were deemed unsanitary to provide guidance to improve sanitation. Assessment data of the number of patients with symptoms were updated and monitored daily, and contamination-control certified nurses were sent to the shelters where there was an increase in the number of patients with symptoms. Comments of the contamination-control certified nurses such as it being important not only to sterilize the fingers with quick drying alcohol disinfectant but to wash with running water were

\section{Figure 3. Water supply system}

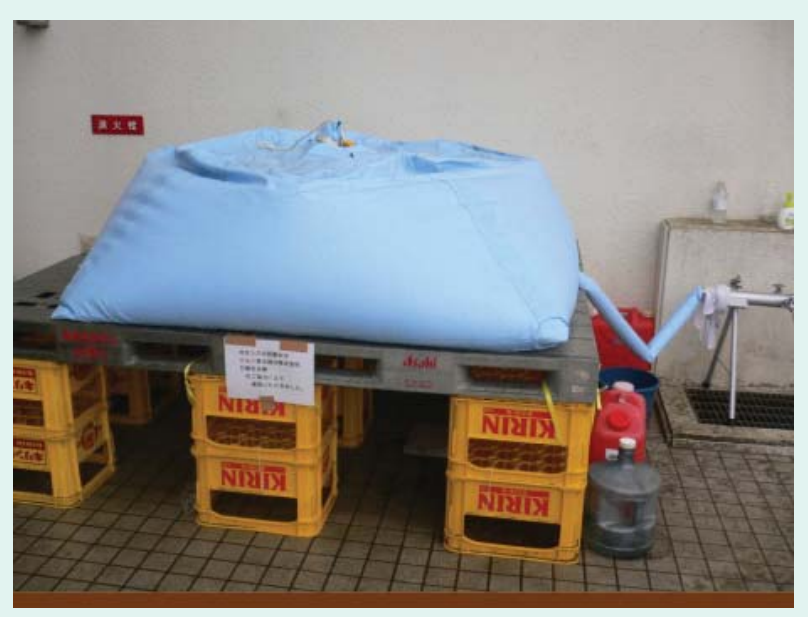

applied. With the total cooperation of the international relief department of the Japanese Red Cross Medical Treatment Center, simple hand-washing facilities were set up at 11 shelters selected from assessment results. These consisted of cloth storage tanks filled with water and connected to a pipe with a spigot (Figure 3). As of 30 September, there had been no outbreak of contamination or proliferation of communicable disease in the Ishinomaki medical district.

\section{DISCUSSION}

A detailed manual that outlines initial response procedures inside the hospital in specific terms was helpful and was clearly connected with the comparatively smooth initial response. The manual included such information as the person and procedure by which critical infrastructure and damage would be checked following the disaster, the chain-of-command structure and contact system, staff actions, each department's responsibilities, where and how much of the necessary materials would be stored, how and by whom they would be deployed, training based on the manual, disaster assistance agreements and enhanced linkage among facilities and pertinent institutions for preservation of hardware and critical infrastructure. These guidelines, however, are only effective for the initial impact of the disaster. It is difficult to foresee all the circumstances that may occur subsequently, and it is therefore impossible to create a manual that covers the entire response to a disaster. Although the details will be omitted here, application issues continued subsequent to the initial impact. As difficulties appeared one after the other, an optimal plan was devised on 
the spot and adjustments were made as problems occurred.

Coordination of medical activities and support for emergency shelters required the cooperation of all medical institutions, Tohoku University, the administration (Miyagi Prefecture government, Ishinomaki municipal government, Higashimatsushima municipal government and Onagawa-cho government), the self-defence forces, the fire department, the police department, businesses and so forth. In order to maintain the logistics function of the Ishinomaki Zone Joint Relief Team task force, which was handling an overwhelming workload, the Japanese Red Cross Society provided the hospital with significant support, dispatching some 1173 people to supplement the task force staff and some 3929 medical personnel between 12 March and 14 August 2011.

There was significant collaboration with the private sector providing support to emergency shelters. In addition to the previously mentioned companies, a huge amount of support was provided by Google, which created software that compiled information about the emergency shelters and the number of people examined based on assessment data. AEON provided medical treatment support buses to visit emergency shelters and first-aid stations, and Nihon Kohden provided Automated External Defibrillators and various test kits and equipment. Other companies such as Medical Expert, Seimens, Shigadry With Earth, and M-Cube and Associates provided other simple test equipment, mats, beds and so forth.

Requirements for disaster response management are: (1) advanced preparation to quickly establish an initial response system; (2) expertise and decisionmaking ability; (3) willingness to stay the course; and (4) the ability to get things done. Achieving (1) above, requires knowledge of the type of damage expected in major disasters, evaluation of responses to past disasters, a realistic manual that hypothesizes the worst possible scenario, training and collaboration with pertinent institutions on a routine basis. Often, individuals do not have enough power to act on their own, so (2) requires the help of experts, superiors, staff and counterparts at pertinent institutions. Number (3) means not being self limiting, not compromising and recognizing that the usual logic does not always prevail in times of emergency. Managers must work tirelessly to inspire trust in others to insure that decisions are accepted and implemented.
Like (2), number (4) suggests that one person cannot do everything, and it is necessary to get a consensus with affiliated and other organizations and create a system of support and collaboration.

There were several problems in standardizing the activities of the Ishinomaki Zone Joint Relief Team, which could possibly become a model case for future major disaster relief activities.

(1) The relief team task force was established in a Japanese Red Cross hospital, allowing for an enormous amount of clerical support to maintain a huge clerical processing capacity. A hospital other than a Red Cross hospital that becomes the headquarters for a major disaster in the future may not be able to provide equivalent functions. Some public means of training clerical staff will probably be necessary.

(2) Collaboration among the 22 members of the task force relied somewhat on personal connections. Developing a means to standardize establishment of integrated collaboration that does not rely on personal connections requires consideration.

(3) Accurate damage information was not centralized and shared quickly, limiting the self-defence forces' rescue efforts. Review of the information conveyance system on the national level is highly recommended.

(4) Because management and/or understanding of the situation in each area depended on the chain of command for each area, there were differences in perception of the situation in different areas. If the task force had monitored the affected sites more closely, they would have been able to address this problem. Also, because the activities of the chain of command were not standardized, there was disparity in management of each area. An area management manual must be prepared without delay.

(5) Collaboration with DMATs did not proceed smoothly. Because DMATs respond to trauma in the initial stage of a disaster, they were not equipped to respond to a disaster 
demanding long term rescue activities, whereby the majority of the patients were suffering from endogenous disease. The DMAT activities outline needs to be reviewed.

\section{Conflicts of interest}

None declared.
Funding:

None.

\section{Reference:}

1. The headquarters for Japan's Earthquake Research Promotion. 今までに公表した断層及び海溝型地震の長期評価 結果一覧2009 (http://www.jishin.go.jp/main/choukihyoka/ichiran_past/ichiran20090109.pdf, accessed on 6 December 2011). 